\title{
The feasibility of using red mud in coatings based on glyptal resins
}

\author{
Liubov Melnyk, Oleksiy Myronyuk, Volodymyr Ratushniy, Denys Baklan \\ Department of Chemical Technology, National technical university of Ukraine "Igor Sikorsky Kyiv \\ Polytechnic Institute”, Peremogy Ave. 37, Kyiv 03056, Ukraine. \\ lubaxtkm@ukr.net
}

Keywords: water vapor adsorption, in situ compounding, pigment, alkyd coating, resin adsorption The possibility of industrial waste - alkaline red mud to be used as the filler of glyptal resins and coatings thereof is considered. It was determined that the most effective way of compounding of said components was in situ combinations during the synthesis of the polymer, providing systems with filling factor up to 36 wt.\% with decreased moisture absorption ability in comparison to the initial resin. It was demonstrated that the most probable cause of this performance increase is the formation of chemical bonds between the hydroxyl groups of glyptal and weak van der Waals bonds between the carbonyl group of the resin and surface groups on red mud.

\section{Introduction}

The so-called "red mud" is the industrial waste that forms during the alkaline processing of bauxite ores at the alumina production. It is a fact, that at least $35-40 \%$ of the processed ore converts into the red mud. [1-5].

The negative environmental influence is caused by the strong alkalinity of the red mud (its $\mathrm{pH}$ can be in range 11-13). Considering the fact, that typically the volumes of such waste are significantly large, this leads to noticeable contamination of soil. [6]

This problem is known for a long time [7], prompting the proposal and development of numerous technical solutions, mainly through the use of this waste as the raw material for other industries: for example, the production of alkaline activation cements, composite concrete and clinkers $[8,9]$.

In the research presented in reference [7], it was shown that the red mud can be successfully used as the reinforcing extender of plastic composites, for example, of polyvinylchloride base. Besides the comparatively low cost of such raw material, the outstanding advantage of it is the content of the bonded water, which varies in the range 4-8 wt. \% [10], providing a certain level of fire retardant properties.

Despite the large body of work on the possible uses of red mud - plastic compounds, the application of this waste material in the formulation of protective and organic coatings has to date not been developed and is limited to its consideration as a pigment [11] or fire- 
retardant additive [12]. At the same time, taking into account the high alkalinity of such waste, there is unanswered question about interphase compatibility in the thin film coating.

In particular, an conceivable interaction between the polymer matrix and the red mud at a molecular level would be of interest. In the work presented in reference [13], it was shown that a certain level of such interactions may be observed when alkyd resins are used, probably, due to the presence of alkyd functional groups in their structure. Taking into account relatively low self-cost of the red mud as raw material, we considered glyptal resins as the film forming agent due to its affordability, relatively low environmental impact and the presence of active acid groups.

The aim of this work is the establishment of the interaction in the system of glyptal resin and the red mud waste depending on the mode of the composite synthesis. The main task of the work is the comparison of the effectiveness of mechanical combination and the combination of components in situ during the polymer synthesis. The realization of this task would lead to the definition of a full-scale technology for the production of protective and decorative coatings as one of the ways of red mud waste disposal.

\section{Materials and methods}

The red mud of PSC "Zaporizhsky aluminium industrial complex" (GPS
47.860921, 35.129808) was employed as the raw filler material in this work.

Its chemical composition was studied by oxide analysis and is characterized by the high content of $\mathrm{Fe}_{2} \mathrm{O}_{3}, \mathrm{TiO}_{2}$, the mixture of alkali and alkali-earth materials with common formula $\mathrm{RO}$ $+\mathrm{R}_{2} \mathrm{O}=8.62$ wt. \% (Table 1$)$.

Table 1. Chemical composition of red-mud

\begin{tabular}{|c|c|c|c|c|c|c|c|c|c|c|}
\hline \multirow[b]{2}{*}{ Probe } & \multicolumn{10}{|c|}{ Oxide content, wt. \% } \\
\hline & $\hat{\rho}_{\mathbf{n}}^{\tilde{n}}$ & 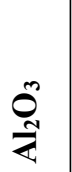 & 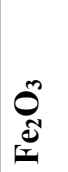 & $\stackrel{0}{e}$ & $\underset{\widetilde{U}}{\stackrel{0}{U}}$ & $\sum_{0,0}^{0}$ & $\oslash_{\mathscr{\infty}}^{\infty}$ & $\begin{array}{l}\overbrace{\pi} \\
\underset{\pi}{Z} \\
Z\end{array}$ & $\begin{array}{l}0 \\
\underline{1}\end{array}$ & $\bar{\theta}$ \\
\hline Red mud & 7.1 & 16.6 & 50.0 & 5.3 & 6.3 & 0.2 & 0.1 & 2.1 & - & 11.7 \\
\hline
\end{tabular}

The analysis of mineralogical composition was performed with DRON-3M XRD analyzer (Fig.1). It was shown that this sample of red mud contains as its main components the minerals goetite $\mathrm{Fe}_{2} \mathrm{O}_{3} \cdot \mathrm{H}_{2} \mathrm{O}$, hematite $\mathrm{Fe}_{2} \mathrm{O}_{3}$, hydrargillite $\mathrm{Al}_{2} \mathrm{O}_{3} \cdot 3 \mathrm{H}_{2} \mathrm{O}$, rutile $\mathrm{TiO}_{2}$, and ilmenite $\mathrm{FeTiO}_{3}$ and is minerally close to the sintered red mud from the study of Feng [14]

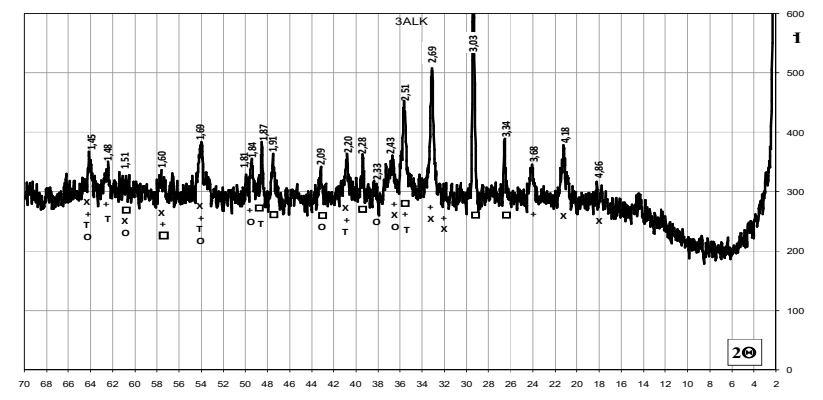

Figure 1. XRD plot of red mud sample. Symbols: $\mathrm{x}$ - goethite, + hematite, $\mathrm{T}-$ rutile, o hydrargillite. 
The basic components for glyptal synthesis used were glycerol and phthalic anhydride. The synthesis was carried out in accordance to a known procedure [15], and the initial weight ratio of components was $1: 1,65$ respectively.

The mechanical combination of components was performed by the addition of the red mud to the already synthesized glyptal resin using a laboratory roll mill. The content of the red mud was 7, 15, 36 and 56 wt. $\%$.

The in situ combination - preliminary mixing of the red mud with the glycerol, consequent addition of phthalic anhydride and the synthesis polymer by the predetermined procedure. The content of the red mud was 15 , 36 and 56 wt. $\%$.

The presence of interaction between the phases of the filler and the polymer was probed by Infrared spectroscopy (Specord IR 75 spectroscope, in wavenumber range from 400 to $4000 \mathrm{~cm}-1)$ with the use of $\mathrm{KBr}$ pellets as the carrier.

A indication of interactions between the polymer matrix and the red mud was the shift or change in the intensity of the absorption bands of the corresponding functional groups of materials present.

To confirm the results of spectroscopic studies, an additional indirect method was used to determine the interaction by adsorption of water vapor [16], which was conditioning samples of the obtained composites in the environment with $90 \%$ humidity for 200 hours with dynamic fixation of the weight changes. The water absorption parameter was determined as the change of the sample weight in wt. \%.

\section{Results and discussion}

Infrared spectra of the synthesized polymer (Fig. 1. (1)) show the absorption bands characteristic for vibrations of O-H bond (3543 $\mathrm{cm}-1), \mathrm{C}-\mathrm{H}$ bond of aromatic ring $(3062 \mathrm{~cm}-1)$, $\mathrm{CH}$ - bonds of corresponding aliphatic groups (2997, $2878 \mathrm{~cm}-1$ ), double bond $\mathrm{C}=\mathrm{O}$ in the carbonyl group (doublet 1738, $1724 \mathrm{~cm}-1$ ), stretching vibrations of $\mathrm{C}-\mathrm{H}$ bonds inside the aromatic ring $(1598,1573 \mathrm{~cm}-1)$, characteristic stretching bands of ethers $-\mathrm{C}-\mathrm{O}-\mathrm{C}-\mathrm{u}-\mathrm{O}-\mathrm{C}-\mathrm{C}$ (1281, $1066 \mathrm{~cm}-1)$ [17], residual $\mathrm{OH}$ groups at $1155 \mathrm{~cm}-1$ [18], and out of plane vibrations of aromatic rings $(735 \mathrm{~cm}-1)$. Hence, the polymer obtained is an aromatic polyester and was verified to be the targeted glyptal resin with the following structure (Fig.1), accordingly to reference [19].

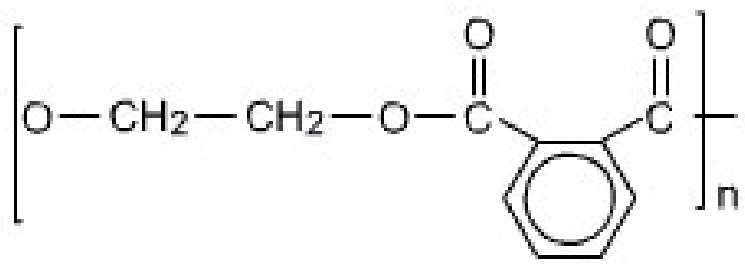

Figure 2. The general structure of glyptal polymer.

The infrared spectra of the red mud have a wide absorption band at 3000-3500 cm-1, which corresponds to bond stretch vibration of the $\mathrm{O}-\mathrm{H}$ bond of absorbed water and related $\mathrm{H}-$ $\mathrm{O}-\mathrm{H}$ bending band $(1450 \mathrm{~cm}-1)$. The spectrum 
also contains small $\mathrm{C}=\mathrm{O}$ peaks of carbonates at $1750 \mathrm{~cm}-1$.

The occurrence of weak van der Waals bonds between the carbonyl group of the glypthalic polymer and the active centers of the filler surface was observed during the mechanical combination process. This fact is proved by the shifting of a vibrational band of carbonyl group from $1738 \mathrm{~cm}-1$ to $1715 \mathrm{~cm}-1$ at the filler concentration level 56 wt. \% (Fig. 3.).

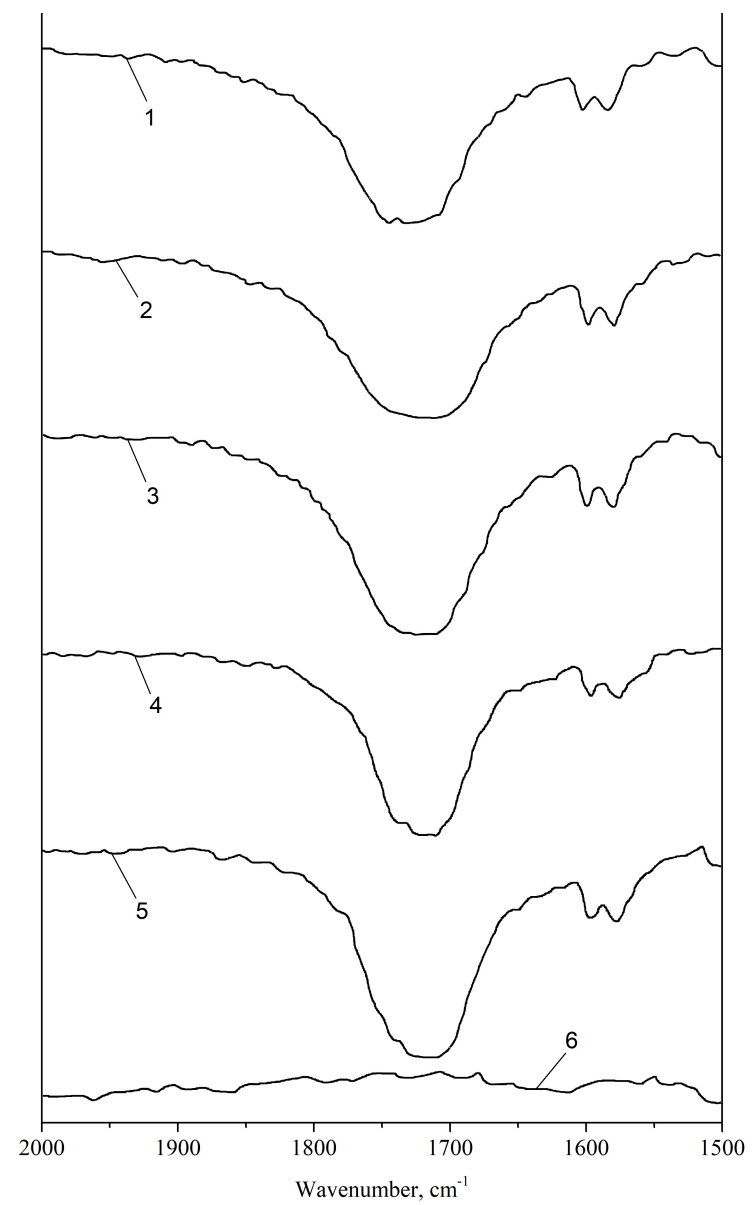

Figure 3. IR spectrum of glyptal-bauxite mechanically mixed compositions: 1. - unfilled glyptal 2. glyptal with 7 wt. \% red mud load 3 - glyptal with 15 wt. \% red mud load 4 - glyptal with 36 wt. \% red mud load 5 - glyptal with 56 wt. \% red mud load, 6 - red mud.
It should be noted that the spectrum of glyphthalic resin almost completely masks the spectrum of the filler. The wide absorption band at $3450 \mathrm{~cm}-1$, which is corresponding to the vibrations of the surface $\mathrm{OH}$-groups of the filler (Fig. 3,6) is almost completely obscured in the spectra of the compositions.

In the spectra of compositions, obtained from the in situ formulations (Fig. 4), the shift of carbonyl peak to $1729 \mathrm{~cm}-1$ at the $56 \mathrm{wt}$. \% loading also can be noted.

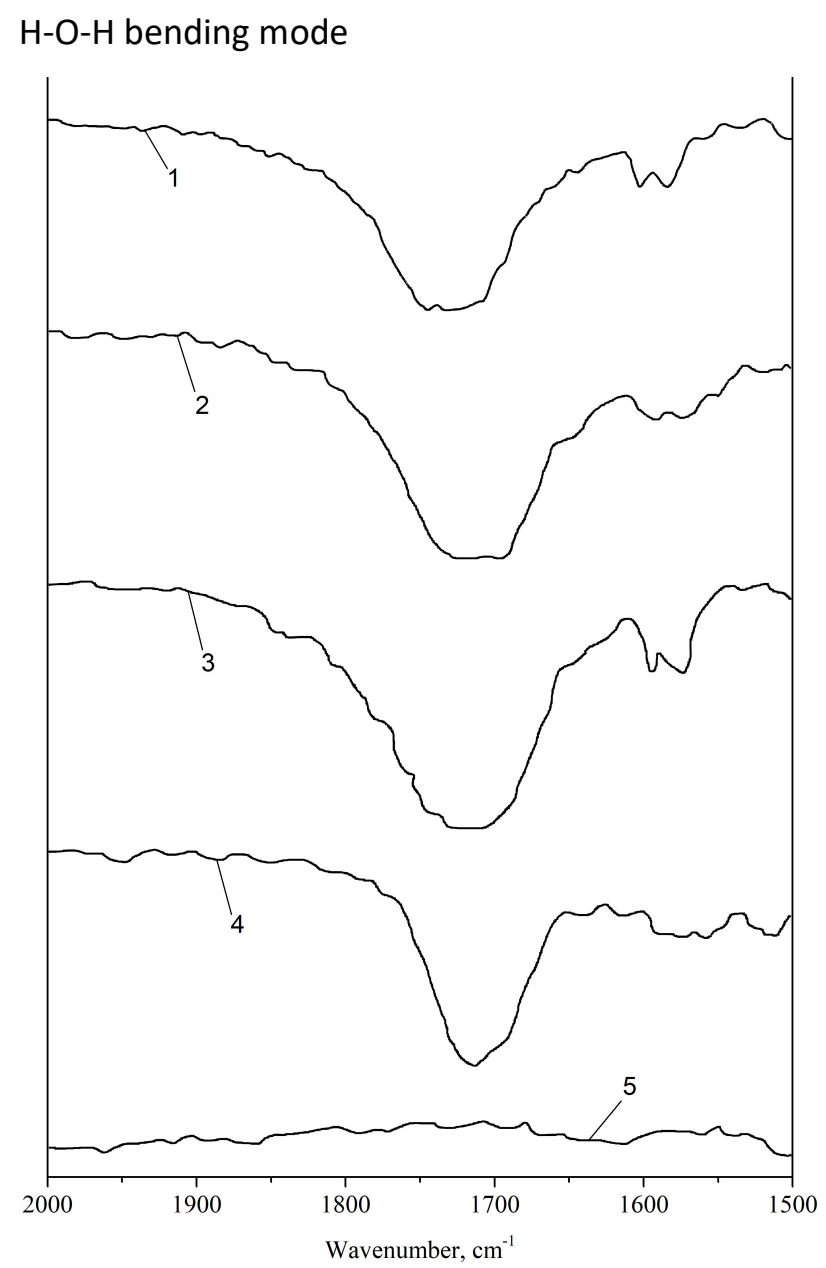

Figure 4. IR spectrum of glyptal-bauxite co-synthesized compositions: 1 - unfilled glyptal 2 - glyptal with 15 wt. $\%$ red mud load 3- glyptal with 36 wt. \% red mud load 4 glyptal with 56 wt. \% red mud load 5 - red mud. 


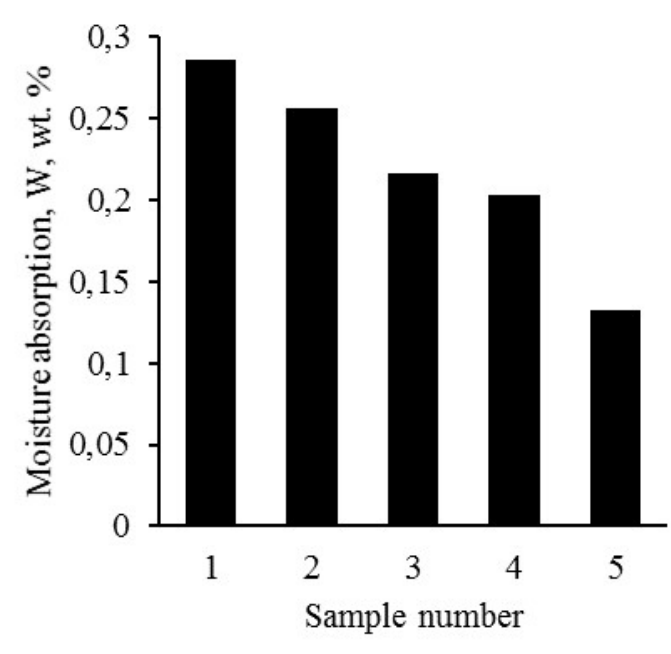

Figure 5. Water vapor adsorption of glyptal mechanically mixed composites: 1 - Mechanics 56\%, 2 - Mechanics $15 \%, 3$ - Mechanics 36\%, 4 - Resin, 5 - Mechanics 7\%.

It was determined that the value of the specific absorption of water vapors by the films obtained depends on their composition. In the case of systems, that were obtained by the mechanical combination (Fig. 5), the plot of the absorption curve is similar to the curve of unfilled resin (3) and, as evident, is defined by processes of molecular diffusion of the moisture inside the polymer material. However, at the 7 wt. \% content of red mud in the composition the value of the peak absorption (after 200 hours) is decreased by $34 \%$ in comparison to the pristine resin and those compositions, that have 15 and $36 \mathrm{wt}$ \% load show values of absorption close to those of the native resin. In the case of $56 \mathrm{wt}$. $\%$ load, the absorption is significantly increased: by $25 \%$. The most probable reason for such an increase may be considered the lack of the resin for the full coverage of the red mud surface, leading to the formation of the inner capillary structure in such systems. Taking into account the high polarity of the red mud surface, such structures will be subjected to capillary condensation.

In the case of compositions, obtained by in situ formulations, these trends are more evident (Fig. 6).

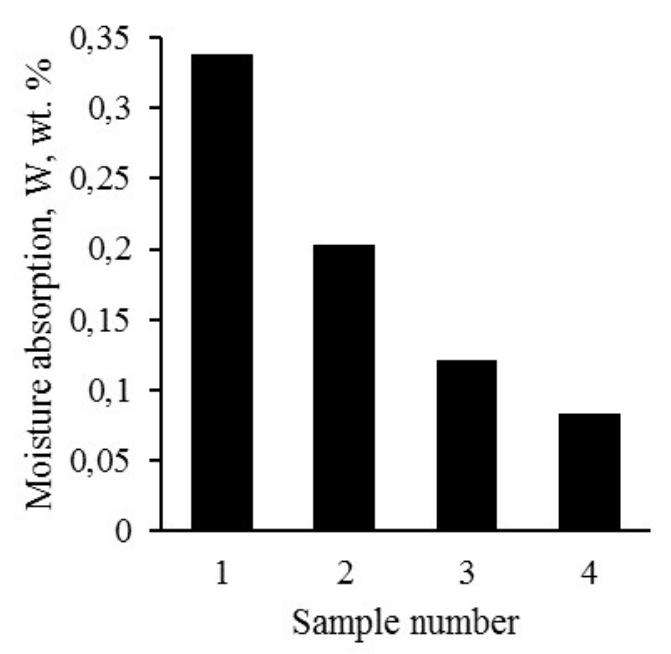

Figure 6. Water vapor adsorption of glyptal composites obtained in situ: 1 - Synthesis 56\%, 2 - Resin, 3 Synthesis $7 \%, 4-$ Synthesis $36 \%$.

At the red mud content 7 and $36 \%$ the water absorption after 200 hours is decreased by 40 and 48 wt. \% accordingly. At the same time, at the red mud content 56 wt. \% the absorption value is increased almost 1,7 times in comparison to the resin.

It is evident, that at the minor loads ( $7 \mathrm{wt}$ $\%$ for the mechanical combination and 7 and 36 wt. $\%$ for the combination in situ) the decrease of absorption values is caused by the interaction of the active functional groups of the resin with the hydroxyl groups of the red mud surface making them less available for hydrogen 
bonding with adsorbed water. The in situ formulation hence may be considered as the most effective because together with a more significant decrease in adsorption value after 200 hours of testing, the value of the effective concentration of the filler increases. The effective content of the red mud in coating, therefore, is above $36 \mathrm{wt} . \%$, that lets to utilize a more specific quantity of this waste material in the coating composition.

\section{Conclusions}

It was shown that red mud can be used as the filler in the glyptal resin based compositions. The in situ synthesis of the polymer in the presence of the red mud was proven to be the most effective way of these components combination. Effective polymer coatings with the filler loads above 36 wt. \% can be obtained in this way.

There appear to be van der Waals, hydrogen bond and chemical interactions between the red mud and the polymer matrix through carbonyl and hydroxyl groups of the resin and red mud, respectively.

\section{References}

[1] Kalkan E. Utilization of red mud as a stabilization material for the preparation of clay liners. Engineering Geology. 2006;87:220-229.

[2] Power G, Gräfe M, Klauber C. Bauxite residue issues: I. Current management, disposal and storage practices. Hydrometallurgy 2011;108:33-45.
[3] Klauber C, Gräfe M, Power G. Bauxite residue issues: II. options for residue utilization. Hydrometallurgy 2011;108:11-32.

[4] Gräfe M, Power G, Klauber C. Bauxite residue issues: III. Alkalinity and associated chemistry. Hydrometallurgy 2011;108:60-79.

[5] Gräfe M, Klauber C. Bauxite residue issues: IV. Old obstacles and new pathways for in situ residue bioremediation. Hydrometallurgy 2011;108:4659.

[6] Wang L, Sun N, Tang H, Sun W. A Review on Comprehensive Utilization of Red Mud and Prospect Analysis. Minerals 2019;9:362.

[7] Sutar H. Progress of Red Mud Utilization: An Overview. American Chemical Science Journal 2014;4:255-279.

[8] Liu X, Zhang N. Utilization of red mud in cement production: a review. Waste Management \& Research 2011;29:1053-1063.

[9] Sun H, Chen C, Ling L, Memon SA, Ding Z, Li W, et al. Synthesis and Properties of Red Mud-Based Nanoferrite Clinker. Journal of Nanomaterials 2019;2019:1-12.

[10] Wang P, Liu D-Y. Physical and Chemical Properties of Sintering Red Mud and Bayer Red Mud and the Implications for Beneficial Utilization. Materials 2012;5:1800-1810.

[11] Paramguru RK, Rath PC, Misra VN. Trends In Red Mud Utilization - A Review. Mineral Processing and Extractive Metallurgy Review 2004;26:1-29.

[12] Arogundade AI, Megat-Yusoff PSM, Bhat AH, Faiz A. Characterization of red mud-epoxy intumescent char using surface imaging and micro analysis. AIP Conference Proceedings 2015.

[13] Vassiliou P, Argyropoulos TH. Red mud as anticorrosive pigment for metal protective organic coatings. Paper presented at: 5th international exhibition and conference on environment (HELECO'05); Greece. Athens; 2005. 
[14] Feng Y, Yang C. Analysis on Physical and Mechanical Properties of Red Mud Materials and Stockpile Stability after Dilatation. Advances in Materials Science and Engineering 2018;2018:1-14.

[15] Oldring PKT, Tuck N, Deligny P. Resins for surface coatings. Chichester: Wiley Pub; 2000, 226

[16] Duncan BC, Broughton WR. Absorption and diffusion of moisture in polymeric materials. Teddington: National Physical Laboratory; 2007.

[17] Smith BC. Infrared Spectral Interpretation A Systematic Approach. Bosa Roca: Chapman and Hall/CRC; 2018.

[18] Bumbac M, Nicolescu C, Zaharescu T. Thermal and radiation stability of alkyd based coatings used as insulators in the electrical rotating machines. Journal of Science and Arts 2017;1(38):119-130.

[19] Bartkowiak M, Milchert E, Sałaciński Ł. Vegetable Oils in the Production of Biodegradable Alkyd Resins. Mini-Reviews in Organic Chemistry 2019;16:399-404. 